\title{
Role of TOLL-like Receptors in Adjuvant-Augmented Immune Therapies by T. Seya
}

\author{
Edwin L. Cooper \\ Laboratory of Comparative Neuroimmunology, Department of Neurobiology, David Geffen School of Medicine at UCLA, \\ University of California at Los Angeles, Los Angeles, CA 90095-1763, USA
}

\section{Is There an Evidence-based Approach to TOLL and CAM?}

I have two approaches to CAM and therefore to $e C A M$. First as an experimental biologist, I would like to see CAM emerge not as a highly descriptive branch of biomedicine. CAM as a biomedical pursuit should be driven by imaginative probing - a search for evidence through endless questioning. Second, because of my interest in an evolutionary approach, especially to the mysteries of the immune system, I seek to search for origins as a way to understand the length and breadth or vertical and horizontal positions of biomedical phenomena. The extensiveness in either of the four directions provides important clues as to underlying explanations that often serve to strip away the mystique of what are more complex mechanisms in mammals, especially in humans, which after all is what CAM is all about-its essence. Taking the question of TOLL as one infinitesimal example of gene products, we can view signaling with respect to CAM but from the evolutionary position. It was this evolutionary connection that inspired me to pick up where Seya left off. Actually, Seya and co-workers (1) have considered evolutionary questions by examining TOLL in fish. 'Rainbow trout Onchorhynchus mikiss possess two genes encoding putative leucine-rich repeat (LRR)-containing proteins similar to human TLR5. Molecular cloning of these two LRR proteins suggested the presence of a TLR5-like membrane form (rtTLR5M) and a soluble form (rtTLR5S). [They] elucidated the primary structures and the unique combinational functions

For reprints and all correspondence: Edwin L. Cooper, Editor in Chief, eCAM, Distinguished Professor, Laboratory of Comparative Neuroimmunology, Department of Neurobiology, David Geffen School of Medicine at UCLA, University of California at Los Angeles, Los Angeles, CA 90095-1763, USA. Tel: +1-310-825-9567; Fax: +1-310-825-2224;

E-mail: cooper@mednet.ucla.edu of these fish versions of TLR5. Thus, two distinct gene encodes the TLR5 orthologs in fish, one of which has a consensus intracellular domain (TIR)'.

According to Seya et al. (2), 'the TLR system (TLRs, TOLLlike receptors) is essentially a foreign substance-recognition system. Thus, it is expected that many constituents of CAMs can be agonists of TLRs, thereby being possible candidates for oral vaccine adjuvants. Several reports have focused on the molecular mechanism by which CAMs are effective in association with TLRs. For example, Platycodon grandiflorum, a traditional oriental herbal medicine exerts immunostimulatory and antitumor effects. PG, a polysaccharide isolated from $P$. grandiflorum, activates macrophages and induces nitric acid production and mRNA expression of iNOS. PG-mediated nitric oxide production was sustained in macrophages by the TLR4 pathway involving NF- $\kappa \mathrm{B}$ (3). An edible fungus used in traditional medicine, Agaricus blazei, induced expression of IL-12. IL-12 production was induced by a TLR4-dependent fashion in macrophages. Oral administration of Agaricus blazei further enhanced NK activity (4). The TLR signaling system is involved in the functional features of CAMs. If this is the case, functional genomics and proteomics and the comprehension of the cell signaling networks may substantially contribute to the development of molecular evidence-based CAM. The potential application of SAGE, DNA microarrays and the concept of signalosome to CAM systems may lead to the identification and characterization of genes and signaling pathways that are involved in CAM modalities (5)'.

\section{A TOLL Approach to CAM or is it Vice Versa?}

According to Kasai et al. (4), Agaricus blazei Murill, an edible mushroom, shows immunomodulatory and antitumor activities (6-10). The specific objectives of this investigation were as

(C) The Author (2006). Published by Oxford University Press. All rights reserved.

The online version of this article has been published under an open access model. Users are entitled to use, reproduce, disseminate, or display the open access version of this article for non-commercial purposes provided that: the original authorship is properly and fully attributed; the Journal and Oxford University Press are attributed as the original place of publication with the correct citation details given; if an article is subsequently reproduced or disseminated not in its entirety but only in part or as a derivative work this must be clearly indicated. For commercial re-use, please contact journals.permissions@oxfordjournals.org 
follows: (i) to identify the characteristics of the cell population in peripheral blood mononuclear cells (PBMC) stimulated by A. blazei Murill fraction $\mathrm{H}(\mathrm{ABH})$; (ii) to determine the optimal concentration of $\mathrm{ABH}$ required to induce cytokine production in vitro; (iii) to identify the nature of TLR interacting with $\mathrm{ABH}$ on the cell surface; and (iv) to evaluate the influence of $\mathrm{ABH}$ on natural killer (NK) cell activity. In Brazil, this fungus is used as a traditional medicine for the prevention of cancer, diabetes, hyperlipidemia, arteriosclerosis and chronic hepatitis.

The polysaccharides, proteoglycans, polysaccharide-protein complexes, glycoproteins and steroids from A. blazei Murill mycelia and fruiting body extracts possess antitumor cytotoxic activities (8-15). However, the mechanisms of the antitumor functions of these mushroom components have yet to be determined. The bacterial lipopolysaccharide, mycoplasma lipopeptide (MALP-2), interacts with TOLL-like receptors (TLRs) and induces cytokine production. Similarly, Dectin-1, a fungal $\beta$-glucan receptor subunit, has been shown to interact with TLR2 and mediate cell activation $(16,17)$. A. blazei extract was shown to induce cytokine (IL-12) gene expression. Based on these observations, the authors hypothesized that $\mathrm{ABH}$ may interact with TLRs and induce signals for IL-12 production.

In a similar approach, Yoon et al. (18) looked for a TLR-4dependent activation of macrophages by polysaccharide isolated from the radix Platycodon grandiflorum. 'Platycodon grandiflorum is a traditional oriental herbal medicine known to have immunostimulatory and antitumor effects. PG, a polysaccharide isolated from $P$. grandiflorum activates macrophages and $\mathrm{B}$ cells. [They] investigated the membrane receptor and intracellular signaling responsible for the activation of macrophages by PG. Taken together, their results suggest that PGmedicated induction of nitric oxide production and iNOS mRNA expression in macrophages is mediated, at least in part, by TLP4/NF-kappa B signaling pathway'.

\section{Evolutionary Perspectives}

\section{TOLL in a Protostome Invertebrate: Mosquito}

During the latter part of the 20th century, the discovery of mammalian TLRs, homologs of insect TOLL receptors, linked innate and adaptive immunity. This was the first instance that an immune pathway discovered outside of mammals could be superimposed onto the human immune system, thus unifying aspects of evolution of immune competence. In their study on mosquitoes, Christophides et al. (19) have identified 242 Anopheles gambiae genes from 18 gene families implicated in innate immunity and have detected marked diversification relative to Drosophila melanogaster. Immune-related gene families involved in recognition, signal modulation and effector systems show a marked deficit of orthologs and excessive gene expansions, possibly reflecting selection pressures from different pathogens encountered in these insects' very different lifestyles. In contrast, the multifunctional
TOLL signal transduction pathway is substantially conserved, presumably because of counter selection for developmental stability. Representative expression profiles confirm that sequence diversification is accompanied by specific responses to different immune challenges. Alternative RNA splicing may also contribute to the expansion of the immune repertoire.

\section{TOLL/IL-1 in Innate Immunity of Nematode Worm}

There are entire sequences of genomes from several invertebrates (e.g. the fruitfly Drosophila, the nematode Caenorhabditis elegans, the tunicate Ciona, the mosquito Anopheles). In addition, there are established roles of JAK/ STAT signaling in Drosophila immune responses $(20,21)$. Genetic and functional genomic approaches have begun to define the molecular determinants of pathogen resistance in C. elegans (22). For resistance to pathogens, conserved signal transduction components are required and these include a TOLL/IL-1 receptor (TIR) domain adaptor protein that functions upstream of a conserved p38 MAP kinase pathway. This pathway may be an ancestral innate immune signaling pathway found in a putative common ancestor of nematodes, arthropods and even vertebrates. Furthermore, it probably predated the involvement of the well known TOLL signaling pathways in innate immunity. Pathogen resistance in C. elegans offers fertile opportunities for continuous probing into evolutionary and mechanistic insights of signal transduction and function in innate immunity.

\section{Invertebrates (Earthworms) Recognize Pathogens by Germ Line Receptors but there is Yet no Apparent TOLL}

According to Engelmann et al. (23), 'Earthworm innate immunity depends upon small and large leukocytes (coelomocytes) that synthesize and secrete humoral antimicrobial molecules (e.g. lysenin, fetidin, eiseniapore, coelomic cytolytic factor [CCF]; Lumbricin I). Small coelomocytes (cytotoxic) are positive (CD11a, CD45RA, CD45RO, CDw49b, CD54, $\beta_{2}-\mathrm{m}$ and Thy-1 [CD90]; CD24; TNF- $\alpha$ ) but negative using other mammalian markers. Large coelomocytes (phagocytic) are uniformly negative. Specific earthworm anti-EFCC 1, 2, 3, $4 \mathrm{mAbs}$ are negative for Drosophila melanogaster hemocytes and mammalian cells but positive those of earthworms. Coelomocytes contain several lysosomal enzymes involved in phagocytosis and a pattern recognition molecule (CCF) that may trigger the prophenoloxidase cascade a crucial innate immune response. Earthworms and other invertebrates possess natural, non-specific, non-clonal, and nonanticipatory immune response governed by germ line genes. TOLL and TOLL-like receptor signaling is essential for phagocytosis and antimicrobial peptide synthesis and secretion in insects and vertebrates but has not yet been shown to be essential in earthworm innate responses'.

In multicelluar organisms, the phagocytic response plays a major role in immune mechanisms against environmental pathogens and in clearance of apoptotic cells. The innate 
immune system is capable of recognizing conserved microbial structures or products of microbial metabolism [pathogenassociated molecular patterns (PAMPs)] through a set of germ line encoded receptors called pattern recognition receptors (PRRs). The PRRs of the innate immune system, particularly the family of TLRs is responsible for initiating inflammatory responses against invading pathogens. TOLL and TLRs signaling is essential for phagocytosis and antimicrobial peptide production in insects and vertebrates (24-28). TLR is also present in the nematode worm C. elegans; however, antimicrobial peptide expression is independent from TOLL pathway (29). The point of this review therefore is to present some of the recent characteristics of the innate cellular response in earthworms (annelid worms), a complement to humoral immune functions as summarized in the review by Cooper et al. (30). Earthworms possess a pattern recognition molecule $(\mathrm{CCF})$, which may trigger the prophenoloxidase cascade $(29,31)$, a crucial innate response, and an impressive array of other innate responses, but TOLL-like proteins have not yet been discovered.

\section{Vertebrate Ancestors: The Tunicates Typical Deuterostomes}

According to a multiauthored effort (32), the first chordates appear in the fossil records at the time of the Cambrian explosion, nearly 550 million years ago. The modern ascidian tadpole represents a plausible approximation to these ancestral chordates. Therefore, to explain the origins of chordates and vertebrates, Paramvir et al. (32) generated a draft of the protein-coding portion of the genome of the common ascidian, Ciona intestinalis. The Ciona genome contains $\sim 16000$ protein-coding genes, similar to that of other invertebrates, but only half that found in vertebrates. Vertebrate gene families are typically found in simplified form in Ciona, suggesting that ascidians contain the basic ancestral complement of genes involved in cell signaling and development.

Although there is no evidence of adaptive immunity, a search of the Ciona genome reveals a variety of genes that are likely to mediate innate immunity. There are a large number of possible complement genes, including C1q-like and C6-like genes, three TLR genes and a variety of lectin genes. No interleukin or interleukin-receptor genes were identified except for an IL-1 receptor and an IL-17 receptor gene. It is possible that Ciona has evolved distinctive innate-immunity genes, because a search for the protein domains found in vertebrate innate-immunity genes identified a number of Ciona genes that contain these domains in previously unknown combinations. Despite this somewhat negative information, there is evidence of lytic activity in numerous invertebrates that destroy experimental targets (30).

Azumi et al. (33) proposed that the mammalian genome encodes several TLRs, with each TLR responsible for detecting corresponding pathogen-associated molecular patterns (34). The Ciona genome has only three TLR genes, characterized by the extracellular leucine-rich repeat (LRR) motif and the intracellular TIR domain. The genes involved in the TLR signaling pathway have been identified, including MyD88, characterized by the TIR and Death domains, IRAK (IL-1 receptor-associated kinase), TRAF (TNF receptor-associated factor), NFB and IB. Mouse RP105 protein is an atypical member of the mammalian TLR family as it possesses only multiple LRR motifs and no TIR domain. Ten gene models with domain architecture similar to that of RP105 have been identified. As LRR is a motif that also functions in protein-protein interactions and is involved in cell-cell communication, it is conceivable that some of the LRR-containing Ciona genes actually encode cell-adhesion molecules and not pathogen-recognizers.

\section{Receptors and External Agents that can Affect the Immune System}

\section{Innate Sensing from the Perspective of NK Cells}

In a recent commentary by Cooper (35), CAM was viewed with respect to NK cells. According to Medzhitov and Janeway (36), the survival of multicellular organisms is dependent on their ability to recognize invading microbial pathogens and to induce several immune reactions. Recent evidence suggests that an evolutionally ancient family of TLRs plays a crucial role in the detection of microbial infection and the induction of immune and inflammatory responses. According to Beutler et al. (37), in humans, innate immune sensing usually proceeds through the activation of 10 TLRs, which in turn leads to the production of cytokine mediators that create the inflammatory milieu and abet the development of an adaptive immune response.

Each TLR senses a different molecular component of microbes that have invaded the host. TLR4 senses bacterial endotoxins (lipopolysaccharide); TLR9 senses unmethylated DNA, and TLR3 senses double-stranded RNA. Each receptor has a conserved signaling element called the TIR (TIR/resistance) motif that transduces a signal through five cytoplasmic adapter proteins, each of which has a homologous motif. The integration of signals that the receptors emit is a key mechanism that requires resolution with respect to TLRs. By creating random germ line mutations in mice and screening for individual animals with differences in signaling potential, the complex biochemical circuitry of the innate immune response can be unraveled. Currently, more than 35000 germ line mutants have been produced, and 20000 have been screened to predict innate immunodeficiency states (37).

\section{How do CAM Agents Activate NK Cells?}

Takeda and Okumura (38) have recently reviewed CAM and NK cells and asked the question are Toll-like receptors involved? According to them Toll-like receptors (TLRs) function as the pattern-recognition receptors in mammals and play an essential role in their recognition of microbial and fungal components. Ten members of the TLR family have been identified in humans. TLRs activate NK- $\mathrm{NB}$ and other signalling 
pathways, which results in the secretion of various inflammatory cytokines. It has been reported that TLR-2/6 recognize some components of zymosan, but not B-glucan, which result in production of cytokines and chemokines. Thus, TLRs might play important roles in the biological effects of some intaketype CAM agents. This is a very interesting subject for further studies.

TLRs function as the pattern-recognition receptors in mammals and play an essential role in their recognition of microbial and fungal components (39-42). Ten members of the TLR family have been identified in humans. TLRs activate $\mathrm{NK}-\kappa \mathrm{B}$ and other signaling pathways, which results in the secretion of various inflammatory cytokines (39-43). There is also a report that TOLL-like receptors is recruited to macrophage phagosomes and discriminates between pathogens (44). It has been reported that TLR-2/6 recognize some components of zymosan, but not $\beta$-glucan, which result in production of cytokines and chemokines $(45,46)$. Thus, TLRs might play important roles in the biological effects of some intaketype CAM agents. This is a very interesting subject for further studies.

\section{Mechanisms by Which Foods Influence Immune Functions}

According to Kaminogawa and Nanno (46), 'Probiotics ingested may be partially digested in the gut and incorporated into $\mathrm{M}$ cells present in FAE, and then captured by dendritic cells or macrophages in the interfollicular area of PPs. These professional phagocytic cells hold various receptors on their surface capable of binding common structures of microbes, the pathogen-associated molecular patterns (PAMPs). Among the receptors for PAMPs, molecular structure and functions of TLRs (TOLL-like receptors) have been recently unveiled. Ten TLR families (TLR1-TLR10) have been identified and ligands recognized by some TLRs have been determined. TLR2 recognizes peptidoglycans and lipopeptides as TLR4 does lipoteichoic acids and lipopolysaccharides. Moreover, the $\mathrm{CpG}$ oligonucleotides universally detected in bacterial DNA are recognized by TLR9. The signaling response to stimuli recognized by TLRs is mainly mediated by an intracellular adaptor molecule, MyD88 (myeloid differentiation factor 88). Thereafter, the nuclear transport of NF-B (nuclear factor-B) is stimulated and de novo synthesis of cytokines is induced (40). It has been proposed that stimuli through TLR2 activate both JNK (c-Jun N-terminal kinase) and ERK (extracellular signal regulated kinase) and induce production of IL-10, while stimuli through TLR4 activate JNK and induce production of IL-12 (47)'.

\section{TOLL and CAM: Perspectives}

TOLL is universal and has clear evolutionary counterparts as evidenced by its presence in invertebrates and at least in fish as a representative of lower vertebrate, thus there seems to be a dearth of information derived from many invertebrates and vertebrates. This in a sense is curious and that absence of evidence most probably indicates that no investigators have bothered to search. It is highly unlikely that the genes that control the expression of TOLL have hopscotched throughout the animal kingdom making erratic stops here and there. Another clear indication rings from this commentary concerns the modification of TOLL activities by products usually from plants (48-52) since there is very little information on modifications caused by natural animal products (48).

\section{References}

1. Tsujita T, Tsukada H, Nakao M, Oshiumi H, Matsumoto M, Seya T. Sensing bacterial flagellin by membrane and soluble orthologs of TOLL-like receptor 5 in rainbow trout (Onchorhynchus mikiss). J Biol Chem 2004;279:48588-97.

2. Seya T, Akazawa T, Tsujita T, Matsumoto M. Role of TOLL-like receptors in adjuvant-augmented immune therapies. Evid Based Complement Alternat Med 2006;3:31-38.

3. Yoon YD, Han SB, Kang JS, Lee CW, Park SK, Lee HS, et al. TOLL-like receptor 4-dependent activation of macrophages by polysaccharide isolated from the radix of Platycodon grandiflorum. Int Immunopharmacol 2003;3:1873-82.

4. Kasai H, He LM, Kawamura M, Yang PT, Deng XW, Munkanta M, et al. IL-12 production induced by Agaricus blazei fraction $\mathrm{H}(\mathrm{ABH})$ involves TOLL-like receptor (TLR). Evid Based Complement Alternat Med 2004;1:259-67.

5. Ventura C. CAM and cell fate targeting: molecular and energetic insights into cell growth and differentiation. Evid Based Complement Alternat Med 2005;2:277-83.

6. Itoh $\mathrm{H}$, Ito $\mathrm{H}$, Amano $\mathrm{H}$, Noda $\mathrm{H}$. Inhibitory action of action of a (1-6)- $\beta$ D-glucan-protein complex (F III-2-b) isolated from Agaricus blazei Murill ('Himematsutake') on Meth A fibrosarcoma-bearing mice and its antitumor mechanism. Jpn J Pharmacol 1994;66:265-71.

7. Osaki Y, Kato T, Yamamoto K, Okubo J, Miyazaki T. Antimutagenic and bactericidal substances in fruit body of a basidiomycete Agaricus blazei. Yakugaku Zasshi 1994;114:342-50.

8. Fujimiya Y, Suzuki Y, Oshiman K, Kobori H, Moriguchi K, Nakashima H, et al. Selective tumoricidal effect of soluble proteoglucan extracted from the basidiomycete, Agaricus blazei Murill, mediated via natural killer cell activation and apoptosis. Cancer Immunol Immunother 1998;46: 147-59.

9. Fujimiya Y, Suzuki Y, Katakura R, Ebina T. Tumor-specific cytocidal and immunopotentiating effects of relatively low molecular weight products derived from the basidiomycete Agaricus blazei Murill. Anticancer Res 1999;19:113-8.

10. Takaku T, Kimura Y, Okuda H. Isolation of an antitumor compound from Agaricus blazei Murill and its mechanism of action. J Nutr 2001;131: 1409-13.

11. Kawagishi H, Inagaki R, Kanao T, Mizuno T, Shimura K, Itoh H, et al. Fractionation an antitumor activity of the water-insoluble residue of Agaricus blazei fruiting bodies. Carbohydr Res 1989;186:267-73.

12. Ito H, Shimura K, Itoh H, Kawade M. Antitumor effects of a new polysaccharide-protein complex (ATOM) prepare from Agaricus blazei (Iwade Strain 101) 'Himematsutake' and its mechanisms in tumorbearing mice. Anticancer Res 1997;17:277-84.

13. Mizuno M, Morimoto M, Minato K, Tsuchida H. Polysaccharides from Agaricus blazei stimulate lymphocyte T-cell subsets in mice. Biosci Biotech Biochem 1998;63:434-7.

14. Mizuno T, Hagiwara T, Nakamura T, Ito H, Shimura K, Sumiya T, Asakura A. Studies on the host-medicated antitumor polysaccharides. Part XIII. Antitumor activity and some properties of water-soluble polysaccharides from Himematsutake, the fruiting body of Agaricus blazei Murill. Agric Biol Chem 1990;54:2889-96.

15. Kawagishi H, Katsumi R, Sazawa T, Mizuno T, Hagiwara T, Nakamura T. Cytotoxic steroid from the mashroom Agaricus blazei. Phytochemistry 1988;27:2777-9.

16. Gantner BN, Simmons RM, Canavera SJ, Akira S, Underhill DM. Collaborative induction of inflammatory responses by dectin-1 and TOLL-like receptor 2. J Exp Med 2003;197:1107-17. 
17. Brown GD, Herre J, Williams DL, Willment JA, Marshall AS, Gordon S. Dectin-1 mediates the biological effects of beta-glucans. J Exp Med 2003;197:1119-24.

18. Yoon YD, Han SB, Kang JS, Lee CW, Park SK, Lee HS, et al. TOLL-like receptor 4-dependent activation of macrophages by polysaccharide isolated from the radix Platycodon grandiflorum. Int Immunopharmacol 2003;3:1873-82.

19. Christophides GK, Zdobnov E, Barillas-Mury C, Birney E, Blandin S, Blass C, et al. Immunity-related genes and gene families in Anopheles gambiae. Science 2002;278:159-65.

20. Flajnik MF, DuPasquier L. Evolution of innate and adaptive immunity: can we draw a line?. Trends Immunol 2004;25:640-4.

21. Agaisse H, Perrimon N. The roles of JAK/STAT signalling in Drosophila immune responses. Immunol Rev 2004;198:72-82.

22. Kim DH, Ausubel FM. Evolutionary perspectives on innate immunity from the study of Caenorhabditis elegans. Curr Opin Immunol 2005;17: 4-10.

23. Engelmann P, Cooper EL, Németh P. Review anticipating innate immunity without a TOLL. Mol Immunol 2005;42:931-42.

24. Xu Y, Tao X, Shen B, Horng T, Medzhitov R, Manely JL, et al. Structural basis for signal transduction by the TOLL/interleukin-1 receptor domains. Nature 2000;408:111-5.

25. Horng T, Medzhitov R. Drosophila MyD88 is an adapter in the TOLL signaling pathway. Proc Natl Acad Sci USA 2001;98:12654-8.

26. Kocsis B, Emody L. Pathogen-associated molecular pattern of bacteria and its recognition by the host. Hum Immunol 2003;2:10-9.

27. Blander JM, Medzhitov R. Regulation of phagosome maturation by signals from TOLL-like receptors. Science 2004;304:1014-8.

28. Pasare C, Medzhitov R. TOLL-like receptors and acquired immunity. Semin Immunol 2004;16:23-6.

29. Couillault C, Pujol N, Reboul J, Sabatier L, Guichou JF, Kohara Y, et al. TLR-independent control of innate immunity in Caenorhabditis elegans by the TIR domain adaptor protein TIR-1, an ortholog of human SARM. Nat Immunol 2004;5:488-94.

30. Cooper EL, Kauschke E, Cossarizza A. Digging for innate immunity since Darwin and Metchnikoff. Bioessays 2002;24:319-33.

31. Beschin A, Bilej M, Hanssens F, Raymakers J, Van Dyck E, Revets H, et al. Identification and cloning of a glucan- and lipopolysaccharidebinding protein from Eisenia foetida earthworm involved in the activation of prophenoloxidase cascade. J Biol Chem 1998;273:24948-54.

32. Paramvir D, Satou Y, Campbell RK, Chapman J, Degnan B, De Tomaso A, et al. The draft genome of Ciona intestinalis: insights into chordate and vertebrate origins. Science 2002;298:2157-67.

33. Azumi K, De Santis R, De Tomaso A, Rigoutsos I, Yoshizaki F, Pinto MR, et al. Genomic analysis of immunity in a urochordate and the emergence of the vertebrate immune system: 'waiting for Godot'. Immunogenetics 2003;55:570-81.

34. Gilfillan S, Ho EL, Cella M, Yokoyama WM, Colonna M. NKG2D recruits two distinct adapters to trigger NK cell activation and costimulation. Nat Immunol 2002;3:1150-5.

35. Cooper EL. Commentary on CAM and NK Cells by Kazuyoshi Takeda and Ko Okumura. Evid Based Complement Alternat Med 2004;1: 29-34.
36. Medzhitov R, Janeway C Jr. The TOLL receptor family and microbial recognition. Trends Microbiol 2000;10:452-6.

37. Beutler B, Hoebe K, Du X, Ulevitch RJ. How we detect microbes and respond to them: the TOLL-like receptors and their transducers. J Leukoc Biol 2003;74:479-85.

38. Takeda T, Okumura K. CAM and NK cells. Evid Based Complement Alternat Med 2004;1:17-27.

39. Janeway CA Jr. The immune system evolved to discriminate infectious nonself from noninfectious self. Immunol Today 1992;13:11-6.

40. Takeda K, Kaisho T, Akira S. TOLL-like receptors. Annu Rev Immunol 2003;21:335-76.

41. Akira S, Takeda K, Kaisho T. TOLL-like receptors: critical proteins linking innate and acquired immunity. Nat Immunol 2001;2:675-80.

42. Yeh WC, Chen NJ. Another TOLL road. Nature 2003;424:736-7.

43. Oshiumi H, Matsumoto M, Funami K, Akazawa T, Seya T. TICAM-1, an adopter molecule that participates in TOLL-like receptor 3-mediated interferon-b induction. Nat Immunol 2003;4:161-7.

44. Underhill DM, Ozinsky A, Hajjar AM, Stevens A, Wilson CB, Bassetti M, et al. The TOLL-like receptor 2 is recruited to macrophage phagosomes and discriminates between pathogens. Nature 1999;401 $811-5$.

45. Gantner BN, Simmons RM, Canavera SJ, Akira S, Underhill DM. Collaborative induction of inflammatory responses by dectin-1 and TOLL-like receptor 2. J Exp Med 2003;197:1107-17.

46. Kaminogawa S, Nanno M. Modulation of immune functions by foods Evid Based Complement Alternat Med 2004;1:241-50.

47. Agrawal S, Agrawal A, Doughty B, Gerwitz A, Blenis J, Van Dyke T, et al. Different TOLL-like receptor agonists instruct dendritic cells to induce distinct Th responses via differential modulation of extracellular signal-regulated kinase-mitogen-activated protein kinase and c-fos. J Immunol 2003;171:4984-9.

48. Yoon YD, Kang JS, Han SB, Park SK, Lee HS, Kang JS, Kim HM. Activation of mitogen-activated protein kinases and AP-1 by polysaccharide isolated from the radix of Platycodon grandiflorum in RAW 264.7 cells. Int Immunopharmacol 2004;12:1477-87.

49. Okamoto M, Oh-E G, Oshikawa T, Furuichi S, Tano T, Ahmed SU, Akashi S, Miyake K, Takeuchi O, Akira S, Himeno K, Sato M, Ohkubo S. Toll-like receptor 4 mediates the antitumor host response induced by a 55-kilodalton protein isolated from Aeginetia indica L., a parasitic plant. Clin Diagn Lab Immunol 2004;11:483-95.

50. Han SB, Yoon YD, Ahn HJ, Lee HS, Lee CW, Yoon WK, Park SK, Kim HM. Toll-like receptor-mediated activation of B cells and macrophages by polysaccharide isolated from cell culture of Acanthopanax senticosus. Int Immunopharmacol 2003;3:1301-12.

51. Lee KY, Jeon YJ. Polysaccharide isolated from Poria cocos sclerotium induces NF-kappaB/Rel activation and iNOS expression in murine macrophages. Int Immunopharmacol 2003;3:1353-62.

52. Han SB, Park SH, Lee KH, Lee CW, Lee SH, Kim HC, Kim YS, Lee HS Kim HM. Polysaccharide isolated from the radix of Platycodon grandiflorum selectively activates B cells and macrophages but not T cells. Int Immunopharmacol 2001;1:1969-78.

53. Cooper EL. CAM, eCAM, Bioprospecting. The 21st Century Pyramid. Evid Based Complement Alternat Med 2005;2:125-7. 


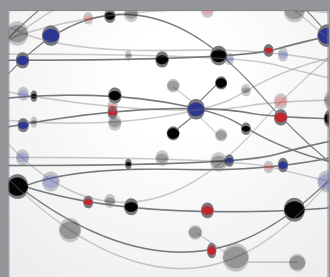

The Scientific World Journal
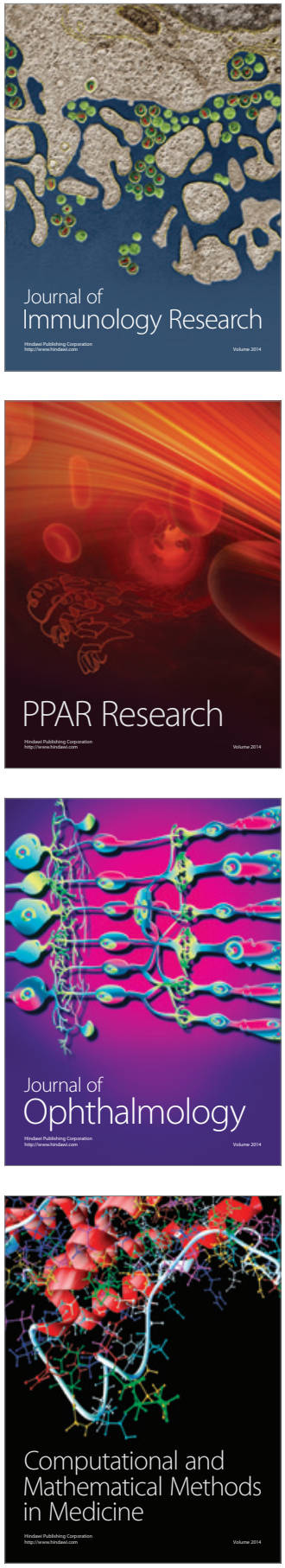

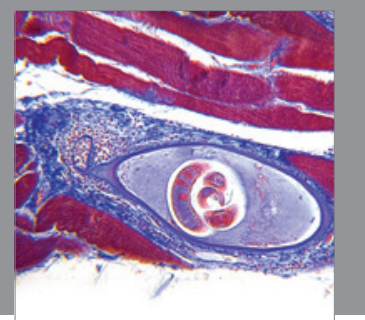

Gastroenterology

Research and Practice
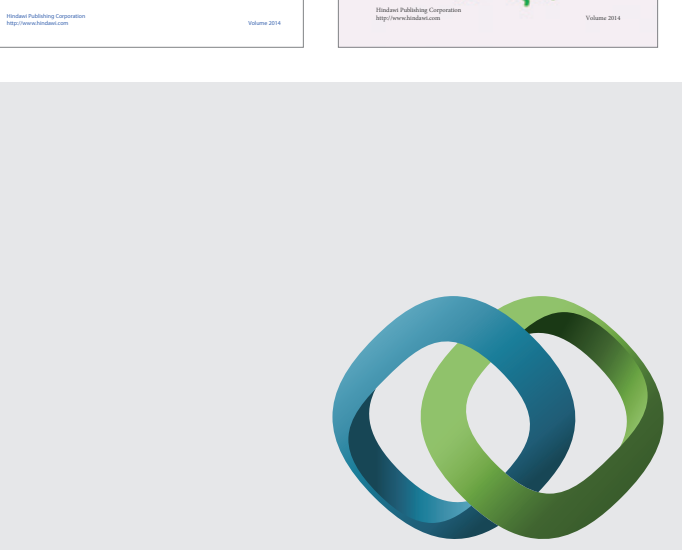

\section{Hindawi}

Submit your manuscripts at

http://www.hindawi.com
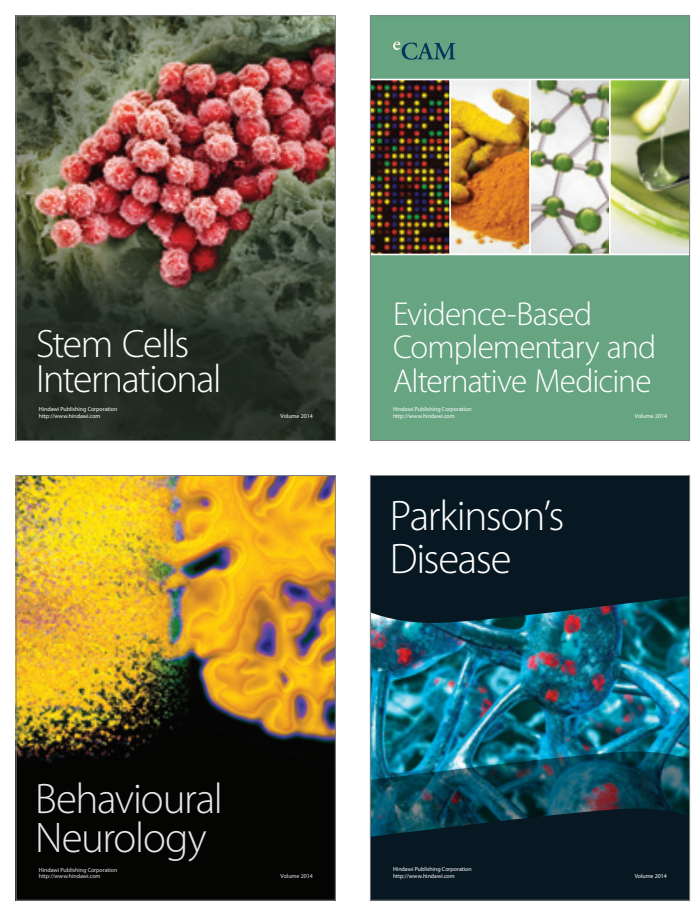

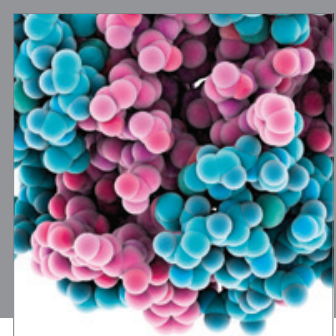

Journal of
Diabetes Research

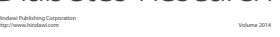

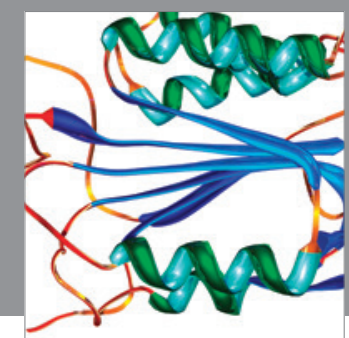

Disease Markers
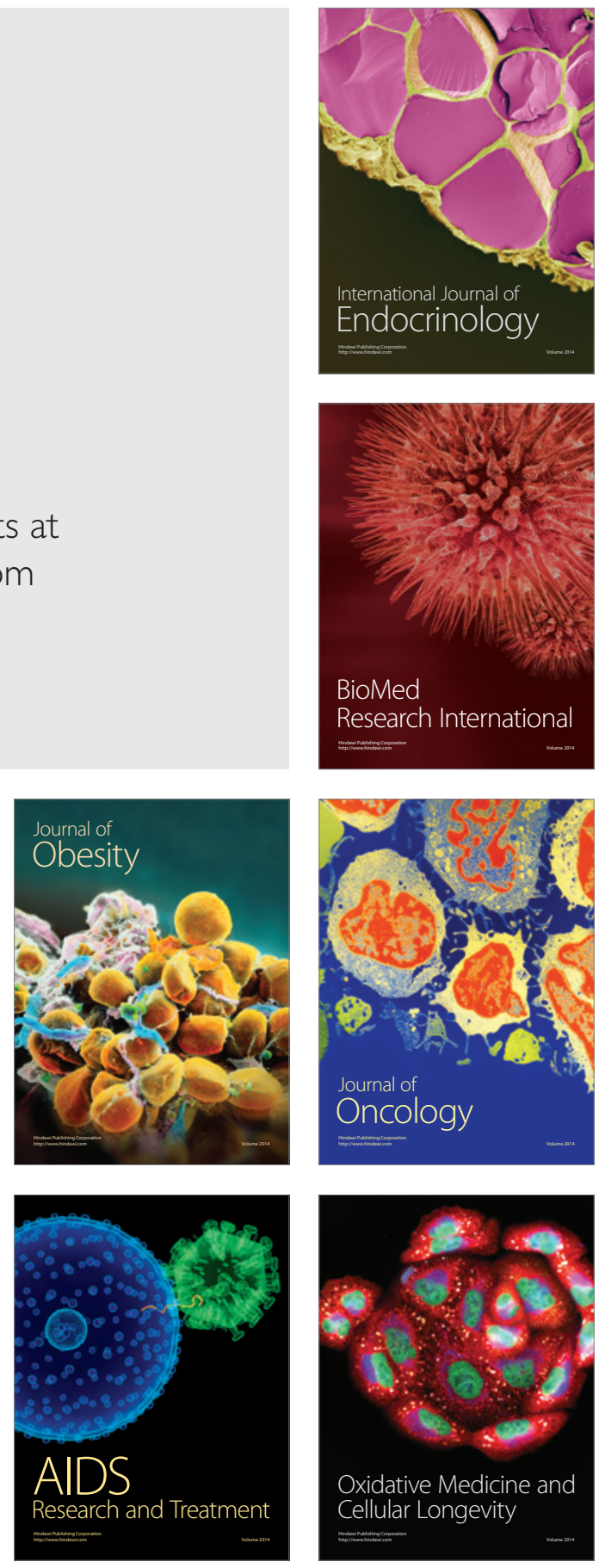